\title{
MERA TOLERANCIA
}

ANTONIO-CARLOS PEREIRA MENAUT Y CAROLINA PEREIRA SÁEZ 
SUMARIO

I. INTRODUCCIÓN. II. RECORDATORIOS. III. PROBLEMAS DE LA TOLERANCIA: TOLERANCIA Y DERECHO. TOLERANCIA Y DERECHOS. LA«PARADOJA DE LA TOLERANCIA». TOLERANCIA Y RELATIVISMO. TOLERANCIA Y RELIGIOSIDAD. IV. A MODO DE CONCLUSIONES: FACTORES QUE FAVORECEN O DIFICULTAN LA TOLERANCIA. V. REFERENCIAS BIBLIOGRÁFICAS. 


\title{
MERA TOLERANCIA ${ }^{1}$
}

\author{
ANTONIO-CARLOS PEREIRA MENAUT \\ Profesor de Derecho Constitucional, U. de Santiago de Compostela
}

CAROLINA PEREIRA SÁEZ

Profesora de Filosofía del Derecho, U. de A Coruña

\section{INTRODUCCIÓN}

Es innecesario recordar la importancia de la tolerancia para la paz social e incluso para la convivencia ordinaria, y tanto para las comunidades políticas como para los grupos menores, familias o personas. Es posible que no sea el sumo ideal ni la meta única, ni última de una comunidad política, pero sin ella está demostrado que las sociedades no funcionan bien.

En nuestra vida real, la estricta justicia no basta para solucionar (y menos para cicatrizar) los problemas difíciles, por eso necesitamos también que estén socialmente difundidas algunas actitudes como la equidad en la aplicación del Derecho, el perdón — sin excluir el olvido—y la tolerancia. Especialmente cuando degenera en «justicierismo» y es considerada sobre todo como retribu-

${ }^{1}$ Reelaboración y ampliación de «Ley, Derecho y Paz Social: el caso de la Tolerancia», por los mismos autores, Notandum 41, mayo-agosto 2015, 79-89. Gracias a D. Negro, A. J. Hegarty, J. I. Martínez Estay y M. Svensson.

Antonio-Carlos Pereira Menaut, Departamento de Derecho Público y Teoría del Estado, Facultad de Derecho, Universidad de Santiago de Compostela. Avda. Dr. Ángel Echeverri, s/n. 15782 Santiago de Compostela. Correo electrónico: acp.menaut@usc.es

Carolina Pereira Sáez, Departamento de Derecho Público Especial, Facultad de Derecho, Universidade de A Coruña. Campus de Elviña, s/n. 15071 A Coruña. Correo electrónico: cpereiras@udc.es 
ción, la justicia llega a lindar con la venganza, por lo que puede producir como respuesta una nueva venganza, y tal vez una espiral de violencia. Los problemas de Sudáfrica e Irlanda del Norte se han ido solucionando a base de no aspirar a la estricta justicia, mientras que en el caso del terrorismo vasco el enfoque ha sido más bien legalista y «justiciero», como si el Derecho pudiera tratar el terrorismo como el hurto o la estafa, volviendo así más difícil la cicatrización de un problema ciertamente grave, el vasco, pero sensiblemente menor que los otros dos antes mencionados. Si con el tiempo ha ido muriendo ha sido más por consunción que porque el gobierno lo solucionara.

Este artículo intenta iluminar los siguientes problemas:

- el mal entendimiento de la tolerancia, así como la realidad de que de facto, y cualquiera que sea la impresión superficial o la «verdad oficial», estamos en una sociedad no muy tolerante, incluso marcadamente intolerante a veces;

- la relación de la tolerancia con otras realidades;

- aspectos clave del actual sistema jurídico-político que favorecen y perjudican la tolerancia;

- los límites del Derecho (y en particular de la ley) a la hora de abarcar la tolerancia.

\section{RECORDATORIOS}

Primero. La palabra«tolerancia», que es latina ${ }^{2}$, parece haber comenzado a usarse con más frecuencia a fines de la Edad Media y principios del Renacimiento. La práctica de alguna forma de tolerancia tiene que ser muy antigua, mucho más que Locke y, a fortiori, que Kant. No tiene sentido preguntarse cuándo comenzó; probablemente, cuando hubo hombres imperfectos que, no obstante, tenían que convivir. Tomás de Aquino se pronunció sobre la tolerancia en algunas ocasiones, pero no fue el primero, ni lo pretendió ${ }^{3}$. Hoy, algunos autores

${ }^{2}$ Del verbo tolero, tolerare, que quiere decir «soportar» y otros significados conexos, bastante cercanos a los que tiene hoy, excepto el erróneo que asimila tolerancia a indiferencia. En los idiomas modernos sigue en la misma línea, como puede verse en el Oxford English Dictionary y otros.

${ }^{3}$ Contra la imprudente exageración de que hay que reprimir todo mal, dice Tomás DE AQUINO: «Ad secundum dicendum quod sapientis legislatoris est minores transgressiones permittere, ut maiores caveantur» (Summa Theologiae, I. ${ }^{2}$-IIae q. 101 a. 3 ad 2) y «(r)espondeo dicendum quod (...) et in regimine bumano illi qui praesunt recte aliqua mala tolerant, ne aliqua bona impediantur, vel etiam ne aliqua mala peiora incurrantur, sicut Augustinus dicit, in II de ordine, aufer meretrices de rebus humanis, turbaveris omnia libidinibus». (Summa Theologiae, II. ${ }^{a}$-IIae q. 10 a. 11). Más sobre Aquino en Svensson; sobre Aquino y Locke en OBerdiek, Tolerance, 69 ss. Más contra esa imprudente exageración en la conclusión, infra. 
hacen depender demasiado la tolerancia del prerrequisito de la autonomía moral kantiana ${ }^{4}$, y, en general, de la Ilustración ${ }^{5}$, que, aunque contenía sin duda elementos que favorecen la tolerancia, pudo igualmente llegar a ser despótica y, por ello, no muy tolerante. Los tecnócratas de la UE, el FMI y del Banco Central Europeo - los modernos déspotas ilustrados - no tienden a serlo.

En realidad la tolerancia es plural y proteica. Puede surgir del altruismo (a su vez subdivisible en varias modalidades), del respeto, del pragmatismo y de muchas fuentes más, hasta del egoísmo inteligente cuando no quiere crearse problemas, o cuando calcula que en el futuro pueda necesitar la tolerancia de los demás. La pereza del gobernante puede indirectamente producir tolerancia, y por eso puede ser bueno (aunque también malo, por otro lado) que el gobernante sea perezoso, legisle poco y no tome demasiado en serio sus propias leyes. Ya decía sabiamente Locke que los reinados de los buenos príncipes habían sido los peores para las libertades de sus súbditos.

No tiene sentido intentar averiguar quién fue el primer autor importante que trató de ella, como si fuera un descubrimiento físico. La tolerancia, aunque sin ese nombre, quizá sin autonomía conceptual y sin un reconocimiento formal, es muy antigua ${ }^{6}$ : se remonta al indeterminado momento en que alguien captó la imperfección humana, la imposibilidad de conseguir todo lo que el gobernante se proponga, la conveniencia de evitar males mayores, la necesidad de templar la dureza de una sanción, las limitaciones de la ley o la necesidad de tener paciencia con los defectos de los demás para convivir. Aparte del Cristianismo, no es

4 Así, Furedi, On Tolerance. El significativo subtítulo es: A Defence of Moral Independence.

5 Se recordará que John LockE, autor de la primera obra importante sobre nuestro tema (la breve Letter Concerning Toleration, de 1685), falleció en 1702, por lo que no fue un ilustrado en el sentido habitual. De hecho, su Segundo Tratado del Gobierno suena en diversos aspectos como una continuación de la línea aristotélico-tomista.

${ }^{6}$ La palabra «tolerancia» en el sentido de permisión o concesión en materia religiosa empezó a emplearse en el siglo XVI —el primer documento jurídico en que aparece es el Pacto de Confederación de Varsovia, de 1573 (cfr. María José Roca, La tolerancia en el Derecho, Madrid, Fundación Registral 2009, pp. 67 y ss.). Tiene un antecedente inmediato en la concordia caritatis —que, a diferencia de la concordia fidei, se refiere sólo al trato político entre confesiones (ibid. pp. 59- 60). Sin embargo, el verbo tolerar había sido empleado mucho tiempo atrás por Tomás DE AQUINO en relación con la libertad religiosa (cfr. Summa Theologiae II. ${ }^{a}$-IIae q. 10, a. 11) y aparece en las fuentes clásicas del Derecho canónico (cfr. RocA. M.J., cit., pp. 34-38), suavizando el rigor iuris (que desaprueba ya el Decreto de Graciano (c. 14, C. XXIII, q.4), recogiendo a su vez un texto de S. Agustín (in liber IV De baptismo, cv.12). En el Derecho canónico la tolerancia aparece junto a otras figuras con las que guarda estrecha relación — dissimulatio, dispensatio, permissio comparativa y permissio approbativa-; lo que la caracteriza es la noción de soportar un hecho o acto negativo para evitar males mayores, y de no implicar aprobación. 
difícil rastrear planteamientos tolerantes en la general visión aristotélica del hombre y la sociedad ${ }^{7}$, en Roma o en el Imperio Otomano.

Es interesante el caso del Imperio Otomano pues duró unos 600 años, seis siglos, en los que se aplicó la pena de muerte por lapidación en muy pocas ocasiones; además los judíos y los cristianos ortodoxos fueron tolerados (de lo contrario, no se explicaría la supervivencia de la religión y el idioma en Grecia). Durante todo el s. XVIII, en el entonces Reino de Galicia, la Inquisición condenó a muerte a un reducidísimo número de personas.

Los grandes imperios, como el romano, el otomano y el británico, practicaron mucho la tolerancia porque no trataron de uniformar sus poblaciones sino de acomodarlas, y la tolerancia es muy adecuada para «acomodar sin uniformar» — justo lo que la UE no hace desde que comenzó la crisis. Similarmente, si en la edad media española no se produjeron demasiadas persecuciones religiosas ni guerras de religión (que luego se producirían en épocas más modernas y avanzadas, y tal vez no por casualidad), fue, en buena medida, por la tolerancia.

Segundo. Como no sea por evitar la malsonante y políticamente incorrecta «intolerancia total» (pocos gustan de proclamarse abiertamente intolerantes), la frecuente expresión «tolerancia cero» no tiene sentido, porque la tolerancia siempre es para lo que es malo o al menos para aquello que desaprobamos. Que en algún momento pueda ser procedente no tolerar en absoluto, es cosa que no se puede descartar a priori, pero habrá que verlo en cada caso, y nunca será sólo porque la conducta sea mala, pues lo bueno no es objeto de la tolerancia sino del premio y la alabanza, lo indiferente tampoco necesita ser tolerado precisamente por ser indiferente, y el ejercicio de un derecho no es tolerancia sino derecho: qui iure suo utitur neminem laedit. «De hecho - dice Furedi- la tolerancia tiene como presupuesto $[\ldots .$.$] el desacuerdo y la desaprobación» { }^{8}$.

Tercero. Nuestro enfoque es personalista. Tanto el que tolera como el tolerado son personas, no abstracciones, teorías o instituciones. Ciertamente, se

\footnotetext{
7 Aunque no conocemos pronunciamientos expresos de ARISTótelEs.

8 «Juzgar es inherente a la tolerancia» (es «inherently judgemental»; GraY, Enlightenment's Wake, p. 28; ver también Furedi, 201. Neil Ross subraya que la tolerancia es para lo que uno desaprueba; como dice él, desapruebo el burca y todo lo que significa, pero nunca iré a arrancárselo a una persona que lo lleve por la calle (Ross, «We need Tolerance, not Respect», Spiked, 19 Nov. 2015). Pero se equivoca al disociar la tolerancia del respeto. El respeto, al que todo ser humano es acreedor, implica respetar siempre a las personas, no necesariamente sus ideas ni prácticas, a menudo poco respetables. Entendemos que sin obligación de respetar, desaparece uno de los fundamentos de la obligación de tolerar. Sobre el respeto, Richard STITH, «The Priority of Respect: How Our Common Humanity Can Ground Our Individual Dignity», 44 Int'l Phil. Q. 165 (2004).
} 
puede decir que una ley, institución o constitución es más o menos tolerante que otra, pero al final todo se reconduce a juicios personales sobre otras personas.

Cuarto. La tolerancia no es de origen jurídico, pero, como el Derecho, pertenece de lleno al terreno de la práctica en sentido aristotélico: «[...] cuando se trata de cosas prácticas el fin no es haberlas considerado todas y conocerlas, sino más bien hacerlas» ${ }^{9}$. Por tanto, nuestros juicios deben ser prácticos: la Constitución norteamericana es buena porque lleva más de doscientos años funcionando razonablemente, no por estar bien escrita o responder a una buena teoría constitucional (que también es cierto). En cambio, las constituciones de Polonia de 1791, española de 1812, alemana de Weimar y española republicana de 1931, no fueron, en realidad, buenas, digan lo que digan el nacionalismo científico o el constitucionalismo de laboratorio.

Quinto. Vivimos malos tiempos para la tolerancia. Tras el 11 de Septiembre de 2001 proliferan en Occidente los planteamientos desfavorables a la tolerancia, aunque no se diga así. En los últimos quince años muchos líderes políticos de muchos países han proclamado la «Guerra total al terrorismo», «war on terror», «guerra total a la delincuencia» o incluso al fraude. En realidad, una persona liberal ${ }^{10}$ y constitucionalista debería ser cuidadosa con la palabra total, pues por algo es la raíz de «totalitarismo». Tony Blair dijo «personal lifestyles free, tough on crime» $\mathrm{y}$ «pro gay rights, tough on crime», planteamiento que tiene el resultado de aumentar la intolerancia respecto a los delincuentes pero también respecto de los que tienen opiniones políticamente incorrectas respecto de personal lifestyles o gay rights ${ }^{11}$. En otro sentido, la postura de Blair viene a ser como decir que seremos completamente intolerantes frente al delito, sin matizar; una actitud nueva en occidente, donde tradicionalmente el Derecho penal distinguía el delito del delincuente y valoraba cada caso.

Existen en nuestro tiempo otras fuentes de intolerancia no relacionadas con el terrorismo, como la seguridad en general, la obsesión con higiene y sanidad, la regulación legal de todo lo imaginable, la aplicación mecánica de las normas,

9 Ética a Nicómaco, 1179 b.

${ }^{10}$ I. e., más comprometida con la libertad política que con el poder o la seguridad. Aquí partimos del liberalismo político clásico, que no coincide con el liberalismo procedimentalista postmoderno de tipo rawlsiano ni con los liberals americanos, más afines a la socialdemocracia europea.

11 T. BLAIR, «What I Have Learned», The Economist, 31 de mayo de 2007: «Today the public distinguishes clearly between personal lifestyle issues, where they are liberal, and crime, where they are defnitely not. It is what I call the pro-gay-rights, tough-on-crime position». En ese punto rozamos la reciente transformación de la izquierda, de izquierda político-económica en izquierda de causas culturales, sexuales y lifestyles, lo que podría llegar a producir su virtual desaparición como contrapeso al capitalismo. 
la dogmática económico-financiera e incluso, curiosamente, ciertas maneras de aplicar algunos de los derechos de última generación, que no piden un terreno libre de la interferencia estatal sino la conformidad con un modelo que se nos propone - $\mathrm{o}$ tal vez se impone, como cuando ciertos derechos son considerados como valores a promover-. Es notable que en España, donde tradicionalmente la tolerancia política era baja y la personal, alta, tras cuarenta años de democracia, la primera sigue puntuando bajo, y la personal ha disminuído, simplemente porque las personas no se perdonan ni se soportan tan fácilmente, porque los gobiernos han descubierto el filón (incluso económico) de regular, controlar, prohibir y sancionar cuanto sea posible, y todo ello va calando en la gente, que parece sentirse cómoda cuando está regulada y lo que hace encaja en alguna de las posibilidades previstas por el legislador.

\section{PROBLEMAS DE LA TOLERANCIA}

Dada la visión commonsensical y proteica de la tolerancia aquí defendida, lejos de nosotros pretender que, una vez correctamente entendida, quede su puesta en práctica libre de todo problema, como si fuera una operación de estricta lógica, o una aplicación de una ciencia exacta por medio de la corespondiente técnica experimental. La tolerancia tiene diversas fuentes, facetas y aspectos, que variarán de un caso a otro. En su aplicación habrá siempre una dosis de sentido común y decisión prudencial, a la que no se llegará por evidencia ni por estricta lógica. Vivimos en la era digital, pero la tolerancia pertenece más bien a la era analógica y, como tal, tiene carencias y no es perfecta (ella misma parte de la imperfección), sistemática ni completamente coherente. La tolerancia está más cómoda con el bonus paterfamilias, el «honrado comerciante», la bona fides, el hombre razonable, the man in the street $\mathrm{o}$ the man on the Clapham omnibus ${ }^{12}$ que con el eficiente funcionario, el gestor o el optimizador de recursos y ganancias. La tolerancia no tiene una solución para todos los casos; por el contrario, presupone la improbabilidad de que tal cosa exista, pues si existiera, bastaría con buscarla.

Primer problema. ¿Es la tolerancia contraria a la igualdad? Pues, en efecto, el tolerado parece estar en una posición inferior al que tolera. Pero aunque aparente a primera vista ser desigualitaria, parte de la igualdad humana básica, de que el tolerado, por mal que haga las cosas, es en el fondo igual de respetable

12 «El hombre que va en el autobús de Clapham» (una línea de autobuses de Londres) fue, y quizá sigue siendo, uno de los standards de razonabilidad de la jurisprudencia inglesa desde la época victoriana. Había otros: el policía razonable, the man in the middle of the road. Eran de carácter commonsensical. El moderno reglamentismo, como el de la UE, no los digeriría fácilmente. 
que nosotros, tiene idéntica dignidad básica, y por eso debemos tolerarlo. El Imperio Británico en la India toleraba casi todo pero prohibió la incineración de viudas. Ciertamente, en ese caso parece haber superioridad moral de unos sobre otros, pero, ¿acaso no es objetivamente cierto que la incineración de viudas, como los sacrificios humanos y otras aberraciones, son posturas objetivamente injustificables, y no dejan de serlo por el hecho de que sea un poder colonial quien los prohíbe? La tolerancia implica la igualdad entre las personas, pero implica también que las posturas y acciones no son iguales, sino unas moralmente mejores que otras. Si en ese caso hubiera habido igualdad y relativismo, los hindúes habrían seguido con esas costumbres. Seguramente había aspectos en los que los hindúes eran moralmente superiores a los ingleses, y seguramente los antiguos britanos también practicaron sacrificios humanos antes de los romanos o del Cristianismo, así que en el fondo de su humanidad serían iguales. La tolerancia no es contraria a la igualdad profunda sino que la presupone: uno de sus argumentos es que estamos juzgando a seres humanos iguales a nosotros. Por eso toleramos algunas acciones que consideradas en abstracto, de no ser por el hombre que las hace, no toleraríamos nunca.

Otra ulterior explicación de ese igualitarismo de fondo es que en la vida todos seremos unas veces los que toleran y otras los tolerados — si bien esto es así entre las personas, pero no siempre entre los países o grupos: por ejemplo, los griegos y los judíos durante el largo imperio otomano fueron siempre los tolerados-.

Segundo. La tolerancia no es neutralidad, y por eso, «porque es decididamente no-neutral respecto del bien», «es ofensiva para el nuevo liberalismo» ${ }^{13}$. Por eso, por considerarla desigualitaria e «imperialista» ${ }^{14}$, algunos se oponen a ella. La tolerancia implica la distinción entre bien y mal, cosa poco digerible hoy. Implica además que quien tolera, de alguna manera asume la capacidad de distinguirlos y aplicar la distinción a la persona tolerada. Es imprescindible distinguir el bien del mal, o, en su defecto, lo correcto de lo incorrecto, o lo que aprobamos de lo que desaprobamos. La tolerancia no puede dejar de partir de la base de que existe esa distinción, así como de nuestra capacidad de percibirla, limitada pero real.

13 Gray, pág. 29. En el «nuevo liberalismo» incluye a Rawls, Dworkin y ACKermann, entre otros. NeHUSHTAN critica mucho el liberalismo neutral y defiende el que llama «perfeccionista», basado en valores.

${ }^{14}$ De ellos, Furedi se detiene sobre todo en Tariq Ramadan, que argumenta en términos de imperialismo, y Anna Elisabeta GALEOTTI, autora de Toleration as Recognition (Cambridge UP, 2002) libro de título significativo en el que la tolerancia acaba por ser otra cosa diferente, el reconocimiento. 
Aquí topamos con el dilema de quienes desde el relativismo proclaman la tolerancia: o la diluyen y des-sustancializan, o en sus vidas prácticas asumen que unas cosas son mejores que otras, unas más tolerables y otras menos tolerables o nada. Quienes defienden que no hay bien y mal, o que no se puede conocer, sino sólo procedimentalismo o relativismo, en los hechos viven conforme a una visión del bien y del mal —la suya- y por eso desaprueban otras. También en nuestra muy relativista sociedad hay un bien y un mal, y es notable que nuestra vida ordinaria esté hoy sometida a más prohibiciones que nunca. En España se regula y prohíbe hoy más que bajo las dictaduras, durante las cuales las prohibiciones se referían básicamente al ejercicio de la libertad política (pero también habría que saber cuánto prohibiría hoy aquella dictadura si sobreviviese hasta nuestros días). Por tanto, en la realidad no hay tanto relativismo como parece, salvo en lo que parece ser su reino y refugio: antropología, sexo, religión, cultura y similares.

Aparte de las miríadas de regulaciones cotidianas que padecemos, también la corrección política restringe el relativismo práctico pues al expandirse, le reduce el terreno; sin que para ello sea obstáculo que la corrección política enarbole precisamente la bandera del relativismo. Relativismo y corrección política pueden, así, resultar hostiles a la tolerancia. El fondo de la cuestión es comparable a lo que sucede con la anomía: nos aseguran que esta sociedad es anómica, pero en realidad sólo lo es en ciertos terrenos, que no suelen molestar al poder político y económico; en los demás, está sometida a más normas y gobernada por muchos más poderes que ninguna otra en la historia de la Humanidad.

Debe notarse que no hay nada de anticonstitucional ni antidemocrático en distinguir el bien del mal (por lo menos, hasta donde seamos capaces), distinción inevitable, como decimos, pues incluso los defensores de la neutralidad y el procedimentalismo, como Rawls, en su vida real la practican. Y la democracia se originó en ambientes donde el bien y el mal se distinguían. En la práctica el problema se plantea menos de lo que parece, pues si nosotros, la gente, no distinguimos mínimamente el bien del mal, acabarán distinguiéndolos, definiéndolos y tal vez imponiéndonoslos, el legislador, los tecnócratas de la Unión Europea, los altos tribunales internacionales, los medios de comunicación o la industria del entretenimiento. Y entonces tendremos una definición de bien/mal más unilateral y artificiosa que la visión popular anterior, pues ésta siempre habrá sido el resultado de un largo proceso y de unas visiones éticas socialmente compartidas durante siglos, no habrá sido creada por ninguna persona o grupo unilateralmente o ex novo, como quien dicta una ley.

Tercero. Lo que se tiene o disfruta por tolerancia no se tiene por derechos o libertades. Es cierto, pero siempre habrá una zona de penumbra en la cual determinados actos o pretensiones que desaprobamos no sean propiamente derechos 
pero, por las razones que sea, no serán prohibidas o descalificadas. Lo contrario lleva al maniqueísmo antes mencionado: que las pretensiones que no se pueden traducir a derechos formales, no existen para el Derecho; son jurídica (y ahora también socialmente) irrelevantes. Hace falta, entonces, hilar fino y evitar el vulgarismo jurídico simplificador, lo que no es fácil cuando vivimos en plena época de vulgarismo jurídico.

Si aunque la ley ordene $\mathrm{X}$, en la práctica hacemos por tolerancia siempre $\mathrm{Y}$, el día que el legislador quiera reponer en vigor $\mathrm{X}$, los argumentos basados en la tolerancia pueden ser incapaces de impedírselo, por no haberse generado un auténtico derecho subjetivo a continuar con Y. Este tema merece un poco más de consideración.

\section{Tolerancia y Derecho}

Entendemos que el intento de hacer ingresar a la tolerancia en el mundo jurídico como un miembro de pleno derecho del mismo, no tiene muchas posibilidades de éxito ${ }^{15}$. Aunque ciertamente afecte al Derecho, la tolerancia no es un concepto jurídico como el usufructo o el dominio público marítimo-terrestre. Intentar captarla por medio del Derecho sería como intentar coger agua con un cesto, pues ninguna ley, constitución ni tratado internacional puede captarla, y además no es exigible ante un juez. Las sentencias no pueden definirla acabadamente, aunque sin ninguna dificultad pueden aplicarla. Con todo, si por un lado incluso los cestos retienen algo de agua, por otro, el Derecho es mucho más que ley, así que no es la ley sola la que tiene que hacer frente a la tarea de abarcar la tolerancia. Si confrontamos la tolerancia con las diferentes fuentes del Derecho, una por una, vemos que la relación que tiene con unas y otras varía mucho. La tolerancia es por un lado pre-jurídica (pues es una actitud humana básica) y por otro post-jurídica (o al menos post-legal), pues entra en función cuando el Derecho ya ha hablado, mitigando la dureza de su aplicación o, en el peor de los casos, volviendo la cabeza para otro lado por razones quizá tan poco elevadas como la pereza. Así, en el caso de un litigio penal, la tolerancia puede estar presente en

15 Nos separamos de visiones como la de Roca cuando trata de discernir un significado jurídico exacto de la tolerancia, distinguiendo tolerancia de iure y tolerancia de facto, y entiende que el lugar de la tolerancia es la ley o medida de carácter general y que tiende a configurarse como verdadero derecho (cfr. María José Roca op. cit., pp. 69, 79, 87 y passim). Sin embargo, como esta misma autora afirma refiriéndose al papel flexibilizador de la tolerancia en el Derecho canónico, no debemos pretender una definición totalmente precisa y rigurosa de la tolerancia si queremos que cumpla esa función (cfr. ibid., p. 49). 
varios momentos: en la interpretación de la ley que haga el juez, en las circunstancias concomitantes que aprecie, en la pena concreta que imponga y, por último, en el trato dado por los carceleros al preso.

La relación de la tolerancia con la ley no es cómoda porque la tolerancia se compadece mal con la norma abstracta y de necesario cumplimiento, pues choca con ambos rasgos. El legalismo provoca intolerancia, como estamos viendo con motivo de la crisis financiera en la UE: al penetrar en la sociedad la mentalidad legalista, muchas personas han disminuido su tolerancia hacia los estados deudores; como dijimos, mucha gente perdona menos, soporta menos, y se muestra incluso vengativa. Añádase la moderna manía de hacer cuentas con el pasado e identificar culpables, como en el caso de la Memoria Histórica española, y dificultaremos que las heridas cicatricen.

En los instrumentos jurídicos no abundan las definiciones de la tolerancia. No se intentó plasmarla en un documento internacional importante hasta 1995 , decretado Año de la tolerancia por la ONU. La Declaración de Principios sobre la Tolerancia de la UNESCO (16 de noviembre de ese año) dice en su art. 1:

«Artículo 1. Significado de la tolerancia.-1.1 La tolerancia consiste en el respeto, la aceptación y el aprecio de la rica diversidad de las culturas de nuestro mundo, de nuestras formas de expresión y medios de ser humanos. La fomentan el conocimiento, la actitud de apertura, la comunicación y la libertad de pensamiento, de conciencia y de religión. La tolerancia consiste en la armonía en la diferencia. No sólo es un deber moral, sino además una exigencia política y jurídica. La tolerancia, la virtud que hace posible la paz, contribuye a sustituir la cultura de guerra por la cultura de paz.

1.2 Tolerancia no es lo mismo que concesión, condescendencia o indulgencia. Ante todo, la tolerancia es una actitud activa de reconocimiento de los derechos humanos universales y las libertades fundamentales de los demás. En ningún caso puede utilizarse para justificar el quebrantamiento de estos valores fundamentales. La tolerancia han de practicarla los individuos, los grupos y los Estados.

1.3 La tolerancia es la responsabilidad que sustenta los derechos humanos, el pluralismo (comprendido el pluralismo cultural), la democracia y el Estado de Derecho. Supone el rechazo del dogmatismo y del absolutismo y afirma las normas establecidas por los instrumentos internacionales relativos a los derechos humanos.

1.4 Conforme al respeto de los derechos humanos, practicar la tolerancia no significa tolerar la injusticia social ni renunciar a las convicciones personales o atemperarlas. Significa que toda persona es libre de adherirse a sus propias convicciones y acepta que los demás se adhieran a las suyas. Significa aceptar el hecho de que los seres humanos, naturalmente caracterizados por la diversidad 
de su aspecto, su situación, su forma de expresarse, su comportamiento y sus valores, tienen derecho a vivir en paz y a ser como son. También significa que uno no ha de imponer sus opiniones a los demás».

Aunque las palabras sean solemnes y suenen bien, la substancia no parece mucha. Reconociendo el esfuerzo de sus redactores, desde el realismo jurídico no se puede hacer un juicio muy favorable. Parece contenerlo todo, pero, acercando la lupa, varias cláusulas tienen escaso contenido real (así, 1.3) Este tipo de declaraciones poco menos que inanes son responsables de que los niños en las escuelas acaben pensando que ser tolerante es ser genéricamente amable y educado, o más o menos demócrata. El párrafo 1.1, bien leído, dice que la tolerancia consiste en... todo lo que podamos desear, incluyendo la exigencia moral, política y jurídica; si bien no aclara cómo será esta última. Las declaraciones como ésta — ensalzarla y simultáneamente reducirla a buena educación- podrían hacer más daño que provecho a la tolerancia porque por un lado, no captan su esencia, y por otro, la diluyen, devalúan y hacen a la gente creer que es otra cosa.

$\mathrm{Ni}$ la mejor de las normas jurídicas escritas puede definir satisfactoriamente la tolerancia. Ello, además, no tendría demasiado sentido, porque la tolerancia implicará a menudo quedarse más acá o ir más allá de la norma, o bien no cumplirla, o sólo a medias, o interpretarla con una benevolencia (o una negligencia) no prevista por el legislador. Desde el momento en que la tolerancia por definición puede implicar incumplir la ley, amortiguar sus efectos o interpretarla de otra forma, mal podrá basarse en la letra de la ley, norma general que nunca prevé su propio incumplimiento. En último extremo, sería más coherente negar la tolerancia que admitirla pero dentro de la ley, pues los derechos, pretensiones o planteamientos que de alguna forma conlleven no sometimiento a la norma, difícilmente podrán basarse en la misma norma. Esto se ve con particular claridad en otra figura, la objeción de conciencia, que también sería más coherente negarla que admitirla pero dentro de la ley (aunque puede ser práctico que la ley la reconozca).

La relación de la tolerancia con la jurisprudencia puede ser fructífera porque se compadece bien con la consideración de cada caso, de cada pena, de cada sanción administrativa. La tolerancia muchas veces implica una buena dosis de casuismo. La tolerancia es una pretensión alegable (según la habilidad del abogado) pero no directamente exigible ante un juez (en ese caso, sería un derecho), si bien éste tiene mucho campo donde practicarla. Como dice la reina Catalina a Wolsey en Enrique VIII, de Shakespeare: «Mi docto lord cardenal, interpretadlo todo con caridad» ${ }^{16}$, y con razón, pues ninguna ley se interpreta sola. El

16 Acto primero, escena segunda, La famosa historia de la vida del rey Enrique VIII, trad. de Luis Astrana Marín. 
intérprete (a menudo, el juez) puede apreciar que summum ius, summa iniuria, o que la justicia total no existe, o que la ley no cubre todos los casos.

En su relación con la equidad, la costumbre y los principios, como ya dijimos, la tolerancia se encuentra cómoda.

En cambio, su relación con los valores es más problemática. Ciertamente, la tolerancia puede ser considerada como un valor, una buena meta; lo que ocurre es que, en general, no está claro que los valores sean una verdadera fuente del Derecho. Añádase que su indefinición y carácter positivo (deben ser "propugnados» ${ }^{17}$, y a veces incluso impuestos) plantean problemas al Derecho, $y$, aunque sean objetivos buenos, si se imponen, dejan poco sitio a la tolerancia. Sin duda, hay que fomentar la tolerancia, que es una excelente meta, pero no está claro que la mejor manera de hacerlo sea proclamándola formalmente como«valor» en una constitución o tratado internacional. Por eso, la tolerancia ayuda a romper un defecto importante de nuestra actual cultura jurídica, el dualismo que no admite sino ley positiva o nada, y que tiene un paralelismo en el terreno de los derechos cuando no se admite sino derechos subjetivos o nada. La historia del Derecho muestra que el dualismo«o ley o nada» nunca tuvo fundamento serio - basta repasar las fuentes del Derecho según los romanos o los anglosajones ${ }^{18}$ — , pero con el constitucionalismo positivista, tomó fuerza y hoy puede verse en la mentalidad de no pocas facultades de Derecho españolas, portuguesas e iberoamericanas, donde frecuentemente se habla el lenguaje de «ley o nada», tomándolo, en realidad, más de los libros que de la vida real.

En cuanto al dualismo «o derechos fundamentales o nada», también dañino para la tolerancia, recordaremos una ingeniosidad efectista anterior a la caída de la Unión Soviética y usada para caracterizar a diversos países europeos según su relación entre libertad y ley: «En Inglaterra, todo lo no expresamente prohibido está permitido; en Francia, todo lo legalmente permitido está permitido; en España, todo lo no prohibido es obligatorio, y en la Unión Soviética, todo está prohibido». Dejando aparte la inexactitud, en España, es aproximadamente eso lo que está sucediendo con la ideología de género y otros capítulos de la corrección política: se ha vuelto obligatoria, con lo que podría resultar que a los discrepantes no siempre se les aplique la tolerancia por ir (supuestamente) contra los derechos fundamentales, núcleo del constitucionalismo occidental. En cuan-

17 Constitución española, art. 1.1: «...propugna como valores superiores...»

18 Las conocidas fuentes según GAYO no necesitan ser reproducidas (Cuatro Comentarios de las Instituciones, Comentario Primero, I,2). Las fuentes jurídicas tradicionales de Inglaterra (sin contar el Derecho producido por la UE ni por el Tribunal de Estrasburgo al interpretar el CEDH) eran el common law, el judge-made law, el statute law (las leyes del Parlamento), la equity, las costumbres, usos y convenciones, y los books of authority. 
to al matrimonio homosexual, lo que ha hecho la reforma legal, y la sentencia constitucional que la avaló, es que, en vez de admitir a los homosexuales al matrimonio a base de varios tipos de matrimonio (homosexual, heterosexual, disoluble, indisoluble, poligámico, monogámico), en alguno de los cuales encajarían, creó un único tipo basado en la clase de unión adecuada a ellos; algo así como«one size fits all», como dicen los norteamericanos. Hoy, no se puede contraer un matrimonio heterosexual porque en el ordenamiento jurídico español eso ha dejado de existir; sólo hay un pacto de afecto entre dos personas cualesquiera $^{19}$, y disoluble más fácilmente que un contrato de permanencia con nuestra compañía telefónica. Al no practicarse una política de tolerancia — dejamos ahora aparte la justicia de la pretensión_- la ideología de género ha pasado en pocos años de virtualmente desconocida a obligatoria por ley en todos los niveles educativos. Aun así, todavía queda espacio para la tolerancia si, por ejemplo, los inspectores no inspeccionan demasiado los colegios, o no revisan mucho el contenido de las clases que se dan en una Universidad.

Ciertamente, una ley injusta puede también ser aplicada de manera laxa y tolerante por jueces y funcionarios, pero el pastor protestante sueco Ake Green en 2004 fue condenado a pena de prisión (luego recurrida con éxito ante el Tribunal Supremo) por decir en un sermón que el matrimonio homosexual no es admisible. No menos conocido fue el caso de unos cincuenta padres de familia alemanes, luteranos, que entre 2006 y 2011 llegaron a sufrir penas de prisión por oponerse a la educación sexual impuesta a sus hijos. La explicación no es que el pastor Green y los padres alemanes toparan con unos funcionarios o policías particularmente intolerantes — que puede ser — sino que los nuevos derechosvalores son como códigos éticos (por tanto, imponen deberes, como es propio de la ética) y son expansivos, tendiendo a la obligatoriedad. La «perspectiva de género» parece haber adquirido el status de base ético-cultural común que ha de ser impartida en todos los centros y a todos los alumnos ${ }^{20}$. «La libertad [hoy]

19 STC 198/2012, de 6 de nov. de 2012, f. j. 9: «[...] la institución matrimonial se mantiene en términos perfectamente reconocibles para la imagen que, tras una evidente evolución, tenemos en la sociedad española actual del matrimonio, como comunidad de afecto que genera un vínculo, o sociedad de ayuda mutua entre dos personas que $[\ldots .$.$] voluntariamente deciden unirse en un$ proyecto de vida familiar común $[\ldots .]$.$» .$

${ }^{20}$ Véase, p. ej., World Health Organization Regional Office for Europe y BZgA, Standards for Sexuality Education in Europe. A framework for policy makers, educational and health authorities and specialists, (German) Federal Centre for Health Education (BZgA), Colonia, 2010; accesible en internet. En España, e igualmente accesible en internet: Abrazar la diversidad: Propuestas para una Educación libre de Acoso Homofóbico y Transfóbico, Subdirección General para la Igualdad de Trato, Instituto de la Mujer, 2015. Contiene partes sobre actuaciones en escuelas y colegios, y sostiene, 
significa control general de las relaciones humanas, para que no nos oprimamos uno a otro» ${ }^{21}$.

En general, la tolerancia está más cómoda con una visión negativa del Derecho (y también, por lo que acabamos de decir, de los derechos) que con una visión positiva, pues muchas veces implicará no ejecutar los mandatos de las leyes, no seguir las metas generales de toda la comunidad política, no aceptar todo lo que se puede derivar, como por goteo, de la Constitución... Por lo mismo, no está cómoda con una visión piramidal del Derecho, con una visión de las constituciones que convierte al ordenamiento jurídico en mero desarrollo de las mismas, ni siquiera con una visión del Derecho como sistema y ordenamiento, pues la tolerancia puede ser imperfecta, fragmentaria y no siempre coherente.

Si queremos una cultura jurídica favorable a la tolerancia es importante también distinguir el Derecho del cumplimiento y ejecución del mismo. La ley y la sentencia pueden verse incumplidas incluso siendo buenas leyes y buenas sentencias. La tolerancia no deroga la ley ni recurre contra la sentencia; simplemente, deja que no se cumplan o mitiga algunos de sus efectos si en ciertos casos resulta demasiado duro o desproporcionado. Nuestros antepasados eran muy flexibles: practicaban la dispensatio o relaxatio legis poenalis (que no era derogación, sólo dispensa de sus efectos) y los indultos, que tampoco derogaban la ley. También admitían una categoría de leyes, las mere poenales, generadoras de una obligación menor y distinta ${ }^{22}$.

Derecho y tolerancia son cosas distintas, como dijimos, pero el Derecho puede serle más o menos favorable. Una cultura jurídica favorable a la tolerancia verá al Derecho como imperfecto y conflictivo, no porque produzca conflictos, sino por verlo como un repertorio de soluciones prudenciales para casos de conflicto, como dijo en muchas ocasiones el gran jurista compostelano Alvaro d'Ors.

El Common Law parte de la imperfección y de que habrá conflictos, y por tanto hay que prever las soluciones. Por el contrario, el actual legislador español gusta de hacer leyes perfectas (de ahí los hábitos de consultar profesores e imitar las normas de los países más adelantados). Una vez hechas, su actitud es esperar que se cumplan, para luego sorprenderse en cuanto comienzan los fallos. Con particular claridad se ve esto en el Derecho constitucional, pues más de una constitución española ha pretendido ser lo más perfecta posible, no dejar nada al

entre otras cosas, que las creencias religiosas no pueden ser obstáculo a estos planes; págs. 20 y 45. Por el momento, no es Derecho vigente.

${ }^{21}$ KaLB, Against Inclusiveness, p. 148.

${ }^{22}$ No obligaban al cumplimiento pero sí a la pena. Por no obligar moralmente, no generaban culpa, pero en caso de sanción había obligación de satisfacerla. No es un concepto exento de problemas (así, si no hay culpa, ¿por qué hay obligación de pagar la sanción?). 
azar y —la de 1978 — ser fuente y control de toda ulterior producción jurídica, con la consiguiente desilusión en cuanto se producen los primeros problemas, agravados hoy por el incumplimiento generalizado y la impotencia de una Constitución (por lo demás, no mala) ante el terremoto político y económico del último decenio. El contraste con la Constitución norteamericana no puede ser mayor, pues no es nada libresca, sino muy deficiente técnicamente, y deja muchos asuntos sin tocar.

Desde el punto de vista de las ramas del Derecho, los lugares más típicos de la tolerancia son el Derecho Canónico, con el que tuvo una relación especial desde hace muchos siglos, y el Derecho Penal.

\section{Tolerancia y derechos}

Para la mentalidad hoy dominante, esto parece tener poco sentido. No se ven ambos términos como contrarios sino como partes armónicas de un mismo pack democrático y constitucional.

Con todo, ¿podrían los derechos ser contrarios a la tolerancia? Hagamos una pregunta comparable: ¿puede la justicia ser contraria a la compasión? A nadie le gusta que se le conceda por compasión lo que se le debe como un derecho de justicia, pero al mismo tiempo, a nadie le gusta ser tratado sólo con justicia, ni recibir nada que no sea un derecho exigible en justicia, ni siquiera los «buenos días» en el ascensor. Ese aspecto — compasión, condescendencia, concesión, gracia, buena educación, y ausencia de exigibilidad jurídica—, lleva a algunos autores a ser críticos con la tolerancia.

Decimos que en determinados casos los derechos y la cultura «de derechos» pueden resultar negativos para la tolerancia, y ello básicamente por dos vías. La primera, muy antigua, consiste en abusar de los derechos o llevarlos al extremo. La segunda, típica sólo del siglo XX (o más bien del XXI) actúa de otra manera: las ideologías o movimientos que desaprueben los derechos comúnmente aceptados, los bona fide rights, el núcleo duro del constitucionalismo liberal, o su equivalente, no tendrían «derecho» (sic) a esperar tolerancia. Y como los derechos fundamentales son parte muy importante de ese núcleo duro, podrían implicar no tolerar al discrepante. Nosotros pensamos que lo tolerado son siempre personas, y por ello discrepamos por principio con la tolerancia cero, por mucha que sea nuestra desaprobación de algo y por importante que sea el derecho atacado, pero queda además otro problema: en realidad, ¿cuáles y cómo son los derechos, hoy? ¿Y cuáles son los comúnmente aceptados? Sin duda, ahora no son aquellas pocas y claras libertades cívicas de 1776, 1789 u otras fechas señeras. Es más, ni 
siquiera los derechos de 1948 se leen igual en 2016, aun cuando el texto literal no haya cambiado. Proclamar que tal o cual pretensión es un derecho no la convierte automáticamente en tal cosa, ni lo incorpora a ningún núcleo duro; las cosas son lo que son, res sunt, pero, una vez que el Derecho ha perdido contacto con la realidad, la persistencia y la presión pueden hacer que los políticos o los jueces pasen a considerar hoy como un derecho lo que ayer era un delito.

Los derechos son variopintos. Las viviendas dignas, las becas y las vacaciones son cosas objetivamente buenas, y muchas constituciones dicen considerarlas derechos, pero, ¿deberá negarse toda tolerancia a quien no los considere tal? ¿Son todos los derechos iguales? ¿Quedará excluído de toda tolerancia, por peligroso para el núcleo central del constitucionalismo, quien considere que el matrimonio debe ser heterosexual? ¿No podrá un pastelero negar una tarta de bodas con figuritas del mismo sexo, sin hacer algo antiliberal y anticonstitucional? ¿Perderán toda expectativa de tolerancia los funcionarios que no quieran oficiar un matrimonio del mismo sexo? (como se sabe, los casos son reales). No faltan autores que piensan así, como Nehushtan. Lo menos que se puede decir de esta postura es que aquel a quien se dé el poder de definir esos derechos y ese núcleo duro, acumulará un poder excesivo, incluso sobre nuestro pensamiento y nuestras posturas morales más delicadas.

Desde el shakespeariano Mercader de Venecia, sabemos que los derechos $\longrightarrow \mathrm{o}$ la manera de exigirlos - pueden producir intolerancia e incluso injusticia. La realidad muestra que el abuso de los derechos es posible, y la Constitución alemana, que algo sabe de ello, prohíbe abusar de ciertos derechos fundamentales ${ }^{23}$. Por tanto, no puede darse por supuesto que en todo ejercicio de derechos su titular practicará la tolerancia. Hay que hacer distinciones, porque hoy en día hay variedad de derechos y maneras de verlos ${ }^{24}$. Primero, los fundamentos de los derechos

${ }^{23}$ Art. 18: quien abuse de ciertos derechos para combatir la democracia, los pierde. Es doctrina tradicional y pacífica del Código Civil español que «La ley no ampara el abuso del derecho o el ejercicio antisocial del mismo» (art. 7). No entraremos ahora en si quien abusa de un derecho está realmente alegando un derecho o más bien su degeneración. Aparte de que «abuso del derecho» es una expresión consagrada, y por ello es mejor mantenerla, es claro que el planteamiento de exigir el máximo de nuestros derechos a nuestros conciudadanos (no así al poder), no favorece la tolerancia.

${ }^{24}$ En cuanto a teoría de derechos y libertades nos remitimos a Lecciones de Teoría Constitucional. En síntesis, se trata de distinguir entre aquello que es más que un derecho (vida, dignidad, libertad, igualdad), los derechos propiamente dichos (debido procedimiento jurídico, ausencia de discriminación injusta, asociación, inviolabilidad de domicilio) y los que en realidad no llegan a la categoría conceptual de derechos, sino más bien prestaciones, aunque el gobernante puede tratarlos como derechos y protegerlos así si lo desea, por medio de una ley respaldada por la correspondiente provisión de fondos (así, diversos derechos sociales). 
— vida, dignidad, libertad profunda, igualdad profunda- no chocan con la tolerancia, e incluso, como la dignidad y la igualdad, figuran entre sus requisitos. Pero en realidad éstos no son derechos en sentido corriente, sino más que derechos, más profundos y básicos que los derechos. Segundo, en general, los derechos de «primera generación» $\mathrm{y}$ «verticales» (frente al estado), como el derecho a no ser condenado sin ser juzgado o a la inviolabilidad del domicilio, por mucho que su observancia aumente no tienen por qué producir intolerancia. En cambio - tercero-, algunos de los variados derechos de hoy, los más de moda en el actual vulgarismo jurídico-constitucional que Glendon llama Rights Talk, pueden ser negativos para la tolerancia. ¿Cómo se produce esa cuadratura del círculo?

Varios pueden ser los caminos. El primero es la extendida consideración de los derechos como cartas de triunfo que producen la rendición automática de todas las cartas de los otros jugadores. Ciertamente, hay ahí una parte de verdad, pues los derechos son para eso, pero de nuevo hay que matizar: ¿de qué derechos hablamos? ¿En qué contexto? ¿Qué resultado producirá la real o pretendida trump card? No es lo mismo detener un litigio si se descubre que no se ha respetado el debido proceso, que imponer irremisiblemente un derecho sobre todos los otros derechos, que de esa forma quedarían anulados o seriamente disminuídos en la práctica. No podemos detenernos más en esto, pero la realidad ha demostrado hasta la saciedad que los derechos no forman un bloque conceptual unitario, que no todos son igual de imprescindibles, ni igual de importantes, ni todos son llave para todos, e incluso los más imprescindibles, como el debido procedimiento jurídico, pueden afectar a otros derechos, ya bloqueándolos, ya facilitándolos.

El segundo es el paso de la verticalidad a la horizontalidad: cuando los derechos fundamentales pasan a ser eficaces contra terceros, mejoramos en algunos aspectos, pero corremos el riesgo de acabar en pie de guerra unos contra otros; el nieto contra el abuelo, el estudiante contra el profesor o el paciente contra su médico.

El tercero es la especificidad de la última generación de derechos, muchos de los cuales son de la personalidad. Al no actuar en el foro o ágora sino en el interior de la persona, y afectar incluso a su identidad, disminuye la posibilidad de que los veamos como algo exterior, prescindible o en lo que se puede ceder. Esa exasperación puede verse en las pretensiones de algunos grupos feministas, como Femen.

El cuarto es la penetración de los nuevos derechos-valores, que se imponen sin admitir límites, por ejemplo, combatiendo toda discriminación hasta en las raíces (aunque sean psíquicas, como es el caso a veces), o expandiendo la ideología de género a todos los niveles educativos. Hasta ahora, los derechos, al moverse siempre dentro del Derecho, eran más sobrios, tenían límites y, así, no penetraban en nuestro interior, pero estos nuevos derechos llegan a producir la criminalización no sólo de la acción sino de la expresión, e incluso, tal vez, de la 
intención (negar el Holocausto, apología del terrorismo, bate speech, bate crimes, etc.). Los derechos, igualmente, nuevos, que se centran en lo estrictamente personal, trabajan en la misma dirección. Basta emparentar esto con la corrección política para aumentar la intolerancia hacia el discrepante y el políticamente incorrecto.

«Cuando la justicia social y la corrección política se encuentran, la vieja idea liberal de que las relaciones entre individuos son asunto puramente personal, queda cancelada. Sólo hay una cosa correcta, y el estado asegurará que se haga. La democracia hoy esta haciéndose más bien intolerante para con el desacuerdo moral y político. Una servil perfección se ha convertido en nuestra manera de pensar $[\ldots] »^{25}$.

Y el quinto y último camino es la expansividad de estas trump cards cuando los derechos protegidos son los de esas últimas generaciones. Los derechos de la personalidad, por ser de la personalidad, definen modelos antropológicos que, si son cartas de triunfo, deben ser universalmente aceptados como bona fide rights, e incluso ser impuestos, no importando qué derechos de sentido contrario se le puedan oponer. En el citado documento español Abrazar la diversidad, el argumento de fondo para sostener que las creencias religiosas no pueden ser obstáculo a la ideología de género y la transexualidad es, básicamente, que éstos son los derechos, ergo, son los triunfos, y por tanto las creencias y las conciencias personales no se le pueden oponer ${ }^{26}$. No se pretende sólo que no sean perseguidos sino, positivamente, que sean asumidos por todos. Algunos comités de la ONU y, en menor medida, la UE, tienen experiencia de esto y parecen buscarlo. Ejemplo: si la ideología de género es correcta, debe ser aceptada por todos, como una base indiscutida, como indiscutido es el due process of law, e incluso enseñada a los niños. Aquí podemos ver un ejemplo de cómo estos derechos no favorecen el tradicional «vive y deja vivir» liberal, sino más bien «confórmate al modelo diseñado por la mayoría» (en la práctica, por el gobierno, los lobbies, los burócratas internacionales o la industria del entretenimiento).

25 Minogue, Servile Mind, pág. 129.

26 Dejemos ahora que lo que la Constitución española, como muchas otras, considera un derecho constitucional, una trump card, es la libertad religiosa, y no la transexualidad. Los defensores de los nuevos derechos intentan convertirlos en bona fide rights a base de declaraciones internacionales que en el mejor caso son soft law, o sentencias judiciales, o presión de los medios sobre la opinión pública. 


\section{La«paradoja de la tolerancia»}

La famosa «paradoja de la tolerancia», comentada por diversos ilustres filósofos, plantea el problema de si la verdadera tolerancia, tomada en serio y llevada a sus últimas consecuencias, implicaría tolerar incluso a la intolerancia. No son pocos los que responden que no. Es una pregunta que recuerda otras paralelas como «¿debe la democracia admitir a los antidemócratas?», o «¿debe el liberalismo admitir a los antiliberales?» Pero, miradas todas con lupa, son paralelas pero no iguales, y la tal paradoja lo parece por un incorrecto entendimiento de la tolerancia. Está planteada como si la tolerancia fuera una creencia filosófica sistematizada, o una forma de gobierno, o un conjunto de instituciones públicas como las de una democracia liberal moderna, ignorando su carácter asistemático, piecemeal y rebelde a la abstracción y a la legalización. También los que defienden la tolerancia cero - aparte de incurrir en intolerancia-, hablan de la tolerancia como si fuera una norma general y abstracta, con unos límites claros, blanco o negro. Nuestra respuesta a si la tolerancia debe admitir la intolerancia es que... depende. ¿Tiene la tolerancia en abstracto obligación de admitir la intolerancia en abstracto? La respuesta, igualmente en abstracto, en principio sería que no, pero el razonamiento abstracto no resuelve estos problemas. Para empezar, nuestro problema se entiende mejor si se plantea de otra manera: ¿tiene la tolerancia que tolerar conductas intolerantes?» $\mathrm{O}$, mejor, ¿tiene que tolerar a personas intolerantes?» $\mathrm{O}$ bien, «¿deben las personas tolerantes tolerar a personas intolerantes?». Pues al final lo tolerado son siempre las personas, y a priori no se puede descartar que a éstas puede ser conveniente tolerarlas hasta cierto punto y en ciertos casos, por intolerantes que ellas sean.

Sin duda, los límites de la tolerancia existen, y más de una vez harán que bajo ningún concepto toleremos ciertas cosas. Pero no son tan fáciles de delinear en la práctica; no son como esas fronteras de países descolonizados a base de dibujar líneas rectas en un mapa. Tampoco es fácil elaborar un elenco exhaustivo de criterios mecánicos para saber cuándo estamos ante algo definitivamente intolerable; un criterio (no el único) podría ser los ataques serios y actuales a los más importantes derechos humanos, pero todavía quedaría mucho por precisar. Y como no podemos prever todos los casos, no podemos descartar todas las posibilidades de que un día tengamos que tolerar hasta cierto punto a un intolerante (no sus ideas en abstracto), como en el caso del caníbal ${ }^{27}$. Sin mucha dificultad el legislador,

27 En «Elogio de la Tolerancia (y de la Imperfección)» desarrollamos el argumento de que aun siendo el canibalismo completamente intolerable, puede darse el caso de que sea prudente tolerar a un caníbal (o, mejor, ex-caníbal). 
igual que cualquiera de nosotros sentado en una bibioteca, puede hacer un listado de ideas, teorías y conductas absolutamente intolerables, como el canibalismo, el infanticidio o el comercio de esclavos, y a continuación ponerlo en una ley, pero no puede saber qué se va a encontrar en cada caso el juez cuando llegue el momento de juzgar al infanticida o al negrero, ni puede saber si habrá circunstancias que agraven o atenúen la pena, ni alarma social o ausencia de la misma, o arrepentimiento, o una enfermedad terminal acabando con la vida del ex-terrorista (no sería el primer caso). El legislador, sentado ante su escritorio como si la sociedad fuera una página en blanco, nunca podrá prever todos los posibles grados del futuro mal, ni cuánta amenaza a la paz social producirá el descubrimiento de un ex nazi o ex caníbal o ex infanticida escondido, ni su arrepentimiento, si se diera; ni para qué sirve ejecutar a un viejo por muchas cosas malas que haya hecho; ni otras muchas miserias, grandezas y tragedias humanas posibles.

Pero este problema de los límites de la tolerancia nos lleva a la relación entre tolerancia y relativismo, pues alguien puede pensar que nuestra crítica a la proposición abstracta «la tolerancia no debe tolerar la intolerancia» se explica por el relativismo.

\section{Tolerancia y relativismo}

Por un lado, queda dicho que la tolerancia no procede de nuestra incapacidad de juzgar, sino, al contrario ${ }^{28}$. Por otro, para muchas personas, hoy, tolerancia implica relativismo, que en algunos autores sería contrapesado por el respeto a unos procedimientos neutros y aceptados por todos. Pero la ilusión procedimentalista — esto es, que la ausencia de una base ética compartida será compensada por unas decisiones sobre los problemas éticos consensuadas según los procedimientos constitucionales-, se ha revelado poco realista. En nuestra vida real, nadie pide nuestro consentimiento para modificar o difundir (cuando no imponernos) una ética, igual que no lo piden para imponernos las destructoras políticas económicas anti-crisis. Nuestras nuevas éticas en realidad nunca son de origen democrático; nunca brotan de la gente sino de los medios, los gobiernos, los lobbies más activos o la industria del entretenimiento, que pueden llegar a imponerla a unos pueblos cuya primera preocupación es, en realidad, el desempleo o la crisis económica ${ }^{29}$. Así, el procedimentalismo no nos ha dejado en

28 También GRAY dice que la tolerancia va contra la corriente de la época porque su práctica está basada en fuertes convicciones morales (p. 28).

29 Como la neutralidad típica de nuestro liberalismo postmoderno por definición no puede decir cuál es la buena vida, quedamos en manos de lo que Gray llama «la opinión bien pensante 
manos de un poder público democrático pero neutro y respetuoso con las reglas que nos hayamos dado todos, sino de unos poderes políticos, económicos o culturales que saben muy bien lo que quieren, tienen sus propias visiones y las difunden e imponen como corrección política, soft law o incluso hard law. Cuando llega la crisis financiera, el poder real muestra poco respeto por los procedimientos y reglas — incluso los de la UE — teóricamente aprobadas por todos.

Según Gray, la experiencia americana de creciente división social desde mediados de los 60, «fundada en la convicción ilustrada de que la cultura común no es una condición necesaria previa de una sociedad civil liberal, muestra que la visión de que la paz civil puede conseguirse por la adhesión a unas reglas abstractas es meramente una ilusión» ${ }^{30}$. Es el viejo problema del acuerdo fundamental y el procedimental, al que nos remitimos ${ }^{31}$. Pero aunque lamentemos la pérdida del anterior acuerdo fundamental y la erosión incluso intencionada a que ha sido sometido, el hecho es que hoy muchas sociedades occidentales parecen haberlo perdido, y por su propia naturaleza no es cosa que se pueda resucitar en un laboratorio e imponer por fiat. ¿Qué hacer, entonces?

El procedimentalismo, por definición, no es lo mejor para la tolerancia, pero tampoco puede ser descartado por completo. En 1998 escribía Paulo Cunha ${ }^{32}$ :

«Los bienes jurídico-penales acaban por ser aquellos que los penalistas deducen [...] del orden constitucional vigente, ya que, no pudiendo pautarse, en una sociedad pluralista y próxima a lo anómico, por autónomos valores de pura axiología, tienen que arrimarse al apoyo constitucional».

En la realidad de 2016 en España (los países no son todos idénticos), lo equivalente a eso no ha funcionado bien, por razones prácticas. Primera, porque, la moderna ley positiva es inestable y efímera, y, segunda, porque el propio legis-

del momento» («the bien-pensant opinion of the day», GraY, p. 30; nosotros entendemos que más bien en manos de grupos de poder).

30 Gray, p. 36. «La idea misma de una cultura común es vista como un símbolo de opresión» (p. 38). Se refiere a los Estados Unidos, pero aquí también sucede. La realidad en España es que en realidad ahora existe una cultura común (incluso demasiado uniforme y poco pluralista), pero que ha sido impuesta por una minoría en poco tiempo.

31 Pereira Menaut, Lecciones de Teoría Constitucional; Pereira Menaut y Pereira Sáez, Teoría Política. Ambas obras parten del liberalismo político clásico.

32 A Constituiçao do Crime, p. 89. Que la obra trate precisamente de Derecho Constitucional y Penal resalta su significado. Cunha no sostiene que el pluralismo cuasi-anómico conduzca a apoyarse en el puro procedimiento, sino en la Constitución. Pero en España la Constitución es vista por los procedimentalistas como un acuerdo básicamente neutral y procedimental, sin que sea obstáculo para ello que tenga importantes partes iusnaturalistas (art. 10.1), frente a pocas partes sólo procedimentalistas. CunHa no es un procedimentalista; ver Political Ethics..., p. 3, «No Republic Without Vertue». 
lador no la respeta. Ante la crisis financiera, ni las leyes, ni la Constitución, ni los Tratados europeos nos protegen; por el contrario, partes de ellas han saltado por los aires o han sido abiertamente ignorados (abundan los ejemplos). Ante las oleadas de refugiados sirios, abundan los europeos que no respetan el Derecho europeo. En estas condiciones, la ley y la Constitución no cumplen la función de producir unas pautas convenidas que, nos gusten o no, al menos fueran sólidas y generalmente respetadas y así aportasen algún sentido a la vida jurídica.

En todo caso, es propio de los juristas bajar a la realidad, tarde o temprano, en nuestra argumentación. Y en nuestra realidad, aunque la cultura sea anómica en el fondo, nuestros comportamientos son muy ordenados, porque están muy controlados. Ello no se ha debido a discusiones populares, ni siquiera parlamentarias, sobre lo debido y lo indebido, sino a que la red de normas administrativas, protocolos de actuación, sanciones, controles y vigilancias, es tan espesa y detallada que gran parte de nuestras acciones es imposible que sean espontáneas; son conductas canalizadas — a veces casi pre-configuradas — , tengan mucho o poco sentido.

Este problema típico de nuestro tiempo — la falta de sentido en casi todo, de la arquitectura a la pintura, favorecida por los vientos de neutralidad y relativismo inmoderados - repercute en el Derecho. Se nota en particular al aplicar la tolerancia y al interpretar los derechos humanos, hoy capaces de admitir cualquier contenido y, paradójicamente, de disminuir nuestra libertad. Cuando se trata de derechos fundamentales, antes que la fundamentalidad de los derechos (eficacia contra terceros, etc.) debería primar la fundamentalidad de su sentido. En un mundo con poco sentido compartido socialmente, la tolerancia se hace más difícil (en realidad, todo se hace más difícil). Si en la sociedad hay una general falta de sentido - y el inmoderado predominio de la ciencia experimental conduce a ello, pues acabará por desencantar hasta las puestas de sol—, no será fácil remediarla a base de leyes positivas y constituciones. Y esto sería así aunque fueran razonables, estables y generalmente respetadas, como la Constitución norteamericana, pero más aun si, como la mayoría, lo son sólo a medias. Las constituciones escritas, aunque sean buenas, no pueden escapar a esto ${ }^{33}$.

${ }^{33}$ El problema es de siempre, pues las normas no se aplican ni interpretan solas. «Las constituciones escritas tienen que ser interpretadas de forma que parezca sensata a los que gobiernan por medio de ellas[...]: no pueden resistir contra las tendencias generales. Las agencias interpretadoras finalmente seguirán la visión [...] dominante entre las élites, e interpretarán la Constitución conforme a ella» (KALB, Tyranny, p. 171) 


\section{Tolerancia y religiosidad}

No son pocos los autores que dicen que la religiosidad misma produce intolerancia, y en particular las religiones monoteístas ${ }^{34}$, pues la creencia en un Dios único y personal sería ya una raíz de intolerancia. Es éste un tema de suficiente calado como para dedicarle un poco más de atención.

Que la religiosidad descarrilada, o mezclada con la política, ha producido en el pasado intolerancia y guerras, no está en discusión. Dejaremos ahora de lado - aunque tal vez no deberíamos- que, como dice gráficamente Minogue, «el pasado es un país extraño; allí hacen las cosas de otra manera ${ }^{35}$, y que por tanto hay que ser prudente en los juicios históricos, no descontextualizar las cosas, y evitar juzgar las Guerras de Religión del siglo XVII o la Inquisición, con las gafas del siglo XXI. Lo que importa es si la religiosidad da también argumentos apreciables en favor de la tolerancia — y los da, especialmente el Cristianismo-, y si las personas religiosas han sido capaces de practicar la tolerancia durante períodos significativamente largos, y la respuesta es que sí; bastante más largos que los períodos contrarios. Lo que importa, así mismo, es saber si otras ideologías, empresas humanas e instituciones no religiosas, han provocado también intolerancias significativas. Dicho de otra manera: desde la religiosidad se ha generado intolerancia, pero ¿se ha generado también desde la irreligiosidad? La respuesta es que en el siglo XX la irreligiosidad ha sido más intolerante y sangrienta que la religiosidad.

De entre las obras recientes, Nehushtan defiende eso en forma enérgica. Omite todas las fuentes de intolerancia no religiosas (precisamente las que importan hoy en Europa) y se centra en las atribuíbles a alguna de las religiones, llevándolas al extremo. Sostiene que la religiosidad misma es intrínsecamente intolerante ${ }^{36}$, que el ser «religioso lleva naturalmente al prejuicio y la intolerancia», aunque haya excepciones ${ }^{37}$, que el Ku Klux Klan (entre otros ejemplos) no fue una aberración sino que resultó «de unas razonables interpretaciones de

${ }^{34}$ La religión oficial romana, politeísta, fue intolerante con el Cristianismo, pero menos por la dimensión religiosa que por la política, pues los emperadores recibían el título de divus, divino (lo cual en algún caso podía ser cómico), y de ahí el culto imperial oficial, al que los cristianos no podían asentir.

35 Servile Mind, pág. 58.

36 Intolerant Religion, pp. 58-119, 123 y passim. Es el argumento del libro, un trabajo casi más«de combate» que académico. El libro no estudia prácticamente la historia, apenas discute casos reales y no estudia los textos de las grandes religiones, que da la impresión de conocer poco. No ignoramos que no todos los que piensan como él llevan las cosas tan al extremo.

37 Nehushtan, págs. 122-123. 
escritos religiosos» cristianos $^{38}$, y que el carácter religioso «de una pretensión jurídica, política o social es siempre una razón para no tolerar esa pretensión» ${ }^{39}$. Tampoco se salvan los objetores de conciencia de base religiosa: el estado liberaltolerante (que opone al liberal-neutral o «pluralista») no debe proteger a los objetores de conciencia, aunque sean tolerantes, para no apoyar así, «aunque sea indirectamente, [otras] instituciones o prácticas de esa religión que son intolerantes ${ }^{40}$.

Todo ello no parece sólido, pero el peor fallo de Nehushtan, para nosotros, es el razonamiento abstracto, que se suma a su "perfeccionismo» ${ }^{41}$. En su libro hay poca atención a la realidad, y en particular a la historia. Y ese fallo produce un planteamiento contrario al sentido común y a nuestra experiencia cotidiana: como decíamos, las amenazas a la tolerancia hoy en Occidente apenas vienen de la religiosidad sino de la lucha contra el terrorismo, la salud, la higiene, la ortodoxia financiera, la UE, el legalismo, la corrección política y la lucha, incluso mental, contra las reales o supuestas fobias que la corrección política encuentra condenables. En nuestro ambiente europeo, en el que una persona puede perder su trabajo por llevar una pequeña cruz, desplegar tanta artillería contra la intolerancia de raíz religiosa es como tomar medidas contra las inundaciones en el Sahara. Durante el siglo XX, los movimientos más intolerantes y sangrientos — con mucha diferencia los peores de la historia humana-, no estuvieron inspirados por la religiosidad sino por el ateísmo: stalinismo, nazismo, maoísmo ${ }^{42}$.

En este tema, hay personas para las que es difícil emitir un juicio frío porque tras septiembre de 2001, mucho del terrorismo y de las guerras tienen, o alegan tener, un trasfondo religioso, y a veces tan explícito que no es trasfondo. Por tanto, como recomendaba Ortega y Gasset, tomemos perspectiva; elevémonos

38 Nehushtan, p. 119. También menciona la Inquisición, pero omite el papel que en su funcionamiento jugaron los reyes, ansiosos por homogeneizar sus poblaciones. Omite los casos en que la Inquisición fue blanda, como en el antiguo reino de Galicia, lo que hizo que fuera refugio para portugueses. Además, sin ignorar los errores e intolerancias de la Inquisición, ha de recordarse el intenso uso político que hicieron de ella los reyes.

39 Nehushtan, p. 201

40 Nehushtan, p. 201.

${ }^{41}$ Liberalismo perfeccionista o basado en valores; NeHUSHTAN, p. 27-28, 55-56 (no confundir su perfeccionismo liberal y político con el tradicional). La suma de perfeccionismo político con abstracción inmoderada, puede concluir como él concluye. Tiene razón al atacar el liberalismo neutral químicamente puro, que ni siquiera existe, pero un perfeccionismo político no templado por el sentido común puede expulsar todo lo que no encaje en él.

42 Nehushtan no dice nada sustantivo sobre la intolerancia por ateos, agnósticos, relativistas o laicistas, por lo que el lector desavisado podría, quizá, deducir que de esas fuentes no podría brotar. 
sobre la vorágine. Es de sentido común: con la sangre de estos años aún caliente, la vista se nos puede nublar.

Yendo al fondo, no encontramos much fire beyond the smoke, como dice el refrán inglés. Veamos por qué.

Como dijimos al inicio, la tolerancia es una noción eminentemente práctica en sentido aristotélico. No estamos aquí hablando de lógica ni física de la materia condensada, sino de si las personas reales en sus vidas reales muestran tolerancia o intolerancia, y en qué grado, en el momento concreto de la interpretación y aplicación. La cuestión es sencilla: mientras los defensores de la compatibilidad entre tolerancia y religiosidad puedan mostrar un número significativo de ejemplos históricos de tolerancia practicada durante un tiempo igualmente significativo, todas las conclusiones contrarias de carácter abstracto no serán concluyentes. En ciencias como las nuestras, las demostraciones prácticas, si no son anecdóticas, pueden llegar a ser trump cards. Discutir sobre religiosidad y tolerancia no es como especular en abstracto sobre la dignidad humana, o sobre si una hipotética república de demonios respetuosos con los procedimientos, more kantiano, funcionaría bien. Mucho más útiles serán los trabajos de los historiadores. ¿Pueden los defensores de la incompatibilidad demostrar que al menos (pongamos) el 50 por cien de los creyentes de una determinada confesión se han mostrado más intolerantes que sus conciudadanos ateos en al menos el 50 por cien de los casos relevantes? Es claro que no. ¿Pueden negar que ha habido largos períodos de gran religiosidad y razonable tolerancia, especialmente antes del surgimiento del estado moderno? Tampoco. Como aquí estamos emitiendo juicios sobre materias prácticas, que tienen que ser vividas, sólo con aducir eso bastaría para refutar la pretendida incompatibilidad intrínseca. Como argumentábamos al principio, si una ley de arrendamientos rústicos funciona, es buena, y por lo mismo, si bajo una determinada confesión religiosa ha habido largos períodos de tolerancia, la pretendida incompatibilidad intrínseca no será cierta, al menos en esos casos.

Con nuestro enfoque personalista y práctico, la asociación automática entre intolerancia y religiosidad no parece tener un fundamento resistente a la crítica. La tolerancia actúa en la fase práctica del Derecho (interpretación, aplicación, ejecución), así como en la convivencia entre las personas. Para afirmar tan rotundamente que la religiosidad producirá intolerancia, hay que estar de antemano seguro de que los intérpretes, aplicadores y, en general, aquellos en cuyas manos estará esa fase práctica, van a ser siempre intolerantes y nunca, ni por pereza, van a mirar para otro lado.

Para nosotros, el florecimiento de la tolerancia requiere como condición sine qua, non admitir la imperfección humana con sus flaquezas o, simplemente, los 
retrasos e insuficiencias en la ejecución de planes, constituciones y leyes. Así, quien niegue un Ser Superior no será intolerante con agnósticos o ateos, pero, si es legalista y perfeccionista, nada le impide serlo (como ya ocurre, a veces, en Europa) con los creyentes, los fumadores, los obesos o los que practican la muy tradicional defraudación tributaria.

Además, la religiosidad humana se ha manifestado con expresiones muy distintas, e incluso una misma religión, sin ningún cambio de fondo, ha sido vivida con muy diferentes grados reales de tolerancia. Las principales confesiones religiosas no coinciden en puntos como el dualismo Dios-César, el grado de tolerancia del mal, el perdón, la venganza y la inviolabilidad de la conciencia personal. En todos esos puntos, y siempre sin desmerecer a nadie, porque de internis nemo iudicat, cualquier análisis revela que el Cristianismo brilla con luz propia.

La religión puede producir intolerancia más fácilmente que otras actividades, como la filatelia, ¿por qué? Por lo mismo que la gente ha dado a veces sus vidas por la religión, pero raramente por la filatelia. El deporte suscita pasiones mayores que la filatelia, pero de por sí nunca debería «pasar de la piel» de la gente, aunque frecuentemente lo haga. La religión afecta mucho y muy radicalmente, a los aspectos más sagrados del ser humano. Por eso, cuando la gente deja de preocuparse por la religión y transfiere esa intensa preocupación a la filatelia, la salud o la seguridad, se vuelve intolerante en eso que ha pasado a importarle más, como esos laicistas que defienden la tolerancia cero para el tabaco. Siempre será más fácil que la intolerancia surja a partir de nuestros aspectos más queridos, sean éstos la religión, la salud o la postmoderna identidad de género. Y si esos aspectos más queridos son compartidos por todos, quizá la gente no vea en ello ninguna particular intolerancia, como sucede hoy con todo lo relacionado con la salud y la higiene.

Decíamos antes que en el siglo XX, la intolerancia basada real o supuestamente en la religión ha producido un número de muertes incomparablemente menor que la basada en la irreligión (nazismo, stalinismo, maoísmo). Las víctimas de la intolerancia religiosa se contaron por miles; las de la intolerancia irreligiosa, por decenas de millones. Ya la Revolución Francesa, en su momento álgido, había sido sangrienta e intolerante. ¿Se ha producido históricamente intolerancia en nombre de la religión, y concretamente del Cristianismo? Sin duda, pero también en nombre de la Revolución Francesa, del deporte y, últimamente, de la ortodoxia financiera europea, que, en su inhumanidad, está llegando a producir, indirectamente, un acortamiento de la esperanza de vida de las personas al poner la austeridad por delante del hombre. En particular, el deporte jamás debería producir intolerancia, por su sumisión a reglas de juego limpio, por su distinción rival deportivo-enemigo personal, su sumisión a un tercero imparcial, y por su abierto rechazo de la perversa noción «el fin justifica 
los medios»; sin embargo, la provoca. Cierto que la intolerancia derivada del deporte ha sido menor que la derivada de las religiones, pero el deporte trata de cuestiones muy periféricas y secundarias para el ser humano y, por otro lado, el fenómeno del gran deporte masivo es muy reciente (posterior al Imperio Británico y a los mass media). Curiosamente, aunque se haya practicado la intolerancia en nombre de la democracia (o su equivalente en la Revolución Francesa) o del socialismo, no hay escuelas importantes que ataquen la democracia por su real o supuesta intolerancia congénita. Y con razón, porque no era congénita - pero tampoco era congénita a la religión, y sin embargo los ataques se recrudecen-.

En el fondo, este problema es paralelo a la relación tolerancia-relativismo. Tiene que ver con esto la «doctrina postmodernista de que el propio concepto de verdad vuelve irracionales las pretensiones de objetividad en un mundo en el que sólo hay una variedad de perspectivas compitiendo unas con otras ${ }^{43}$. Pero, acercando la lupa, y evitando siempre teorizar sobre abstracciones, decíamos que «no hay mucho fuego tras el humo», a no ser el relativismo, por un lado, y la anti-religiosidad hoy tan difundida en Occidente, por otro. Atendamos a la realidad: el Imperio Otomano, cuya religión oficial pasaría por ser la que más favorece la intolerancia, practicó tanto la tolerancia que hacia 1920 había en Oriente Medio muchos más cristianos que hoy. Un dato que debería hacernos pensar: un cristiano ortodoxo cumplidor de sus obligaciones estaba mas cómodo en la Grecia del Imperio Otomano que hoy en la Unión Europea. Ante un hecho así, explicaciones no han de faltar, pero si tenemos mentalidad constitucionalista, se nos debería encender una alarma.

En cuanto al Cristianismo, nadie dirá que su tradicional «odio al pecado y amor al pecador» es negativo para la tolerancia. La lista de contribuciones judeocristianas a la tolerancia sería muy larga: dejar la cizaña crecer con el trigo hasta el final, Dios hace llover sobre buenos y malos, reservar la venganza sólo para Dios, salvar de la lapidación a la mujer adúltera con un «vete y no peques más», no enviar fuego del cielo sobre los hostiles samaritanos, perdonar ofensas y deudas, las obras de misericordia (una de las cuales es visitar a los encarcelados, sin excluir a aquellos que están en la cárcel justamente), devolver al prestatario por la noche la capa que ha entregado en prenda porque no tiene con qué cubrirse, y así sucesivamente.

Por otro lado, históricamente es cierto que en épocas pasadas se han producido crímenes en nombre de «la verdad». Su defensa ha producido intolerancia, como también la de la unidad religiosa, entonces considerada necesaria para la convivencia pacífica y para la construcción de los entonces jóvenes estados. Nadie

${ }^{43}$ Minogue, Servile Mind, pág. 128. 
negará que las guerras de religión de los siglos XVI y XVII fueron particularmente cruentas para su época. Pero ahí la realidad misma nos suministra pistas para comprender el problema. Si, como es indiscutible, la religiosidad no había sido menor en la Edad Media que en el Renacimiento, ¿por qué esas guerras fueron notablemente más cruentas que en el Medioevo? Aparte de factores como el aumento de capacidad destructiva, la respuesta está en el estado. No se trata sólo —aunque también — de la leviatánica concepción del soberano como sumo gobernante de lo religioso y lo político; se trata además de que los modernos estados, con su idea de la competencia universal, tendieron a ver la religión como una materia más de su competencia (por eso pretendían el ius in sacris), y el culto y los estudios religiosos como un departamento más de su maquinaria institucional. Además, aquellos estados veían la uniformidad, y en particular la uniformidad religiosa y de legitimidades, como un muy importante aspecto de los procesos de nation building y state building; y desde su punto de vista, no era tan raro. La idea de homogeneizar era intrínseca al estado, y sigue siéndolo a día de hoy; «la homogeneización [es] inherente a la estatalidad» ${ }^{44}$. Así como fue la dimensión política la que hizo a la religión romana intolerante para con el cristianismo, así en los siglos XVI-XVII fue la nueva dimensión política, el estatismo, la que añadió intolerancia al fuego de los conflictos religiosos. El estado trajo consigo la uniformidad y con ella un aumento de la intolerancia: el principio cuius regio, eius religio pudo favorecer la paz en un determinado momento, pero no es un principio de tolerancia (que luego ésta se practicase o no, varió de un caso a otro, y dependió de diversos factores). En España, su conversión en un estado acarreó lo que hoy consideraríamos como limpiezas étnicas: la expulsión de los judíos (1492) y algo después la de los moriscos (1609-1613), que en la España medieval, aunque más atrasada en muchos respectos, no se habían practicado.

La noción, semejante a la crítica kelseniana al Cristianismo, de que por creer en dogmas religiosos uno tiene que ser personal y políticamente intolerante, no soporta el análisis. Precisamente quien admita dogmas en el nivel sobrenatural mirará con recelo los pretendidos dogmas de los gobernantes terrenales, pues si hay Dios, todo poder humano pasa a ser secundario y queda eo ipso sometido a la posibilidad de ser juzgado. Con su sola existencia, los actuales «dogmas» económicos y de corrección política, que no escasean, desmienten a Kelsen y los demás

${ }^{44}$ Negro, Historia de las Formas del Estado, pág. 303. Huelga señalar que los estados totalitarios llevan esto al máximo: al perseguir «la homogeneización de los espíritus, el Estado Totalitario es enemigo [...] de la libertad de la conciencia [...]» (Negro, pág. 320). Ya Arendt señaló el carácter homogeneizador de los estados nacionales: «Estado Nacional y Democracia», pág. 192. También la corrección política produce homogeneización espiritual y cultural, como subraya Minogue en The Servile Mind. 
que piensen así. Acabamos de experimentarlo en la crisis financiera europea: si por encima de la ortodoxia económica no hay exigencias religiosas ni morales, el gobierno por la economía se vuelve dogmático, inhumano y opresor ${ }^{45}$.

\section{A MODO DE CONCLUSIONES: FACTORES QUE FAVORECEN O DIFICULTAN LA TOLERANCIA}

La realidad muestra que mientras unos factores y actitudes forman un caldo de cultivo y son más favorables a la tolerancia, otros le son más desfavorables.

Hemos dicho que, hablando en general, antes del estado había más tolerancia, y que incluso las actitudes modernas e ilustradas pueden indirectamente generar intolerancia, pero no porque las personas sean necesariamente más intolerantes en una época que en otra (aunque pueda ser así a veces). Hoy, no poca gente cree que todo mal e imperfección pueden y deben ser erradicados de la faz de la Tierra sea como sea, y que el encargado de hacerlo es el gobierno; aquí, sin embargo, sostenemos que el deber de impedir el mal no es absoluto e incondicionado, e incluso podría ser que la tolerancia del mal fuera alguna vez lo más recomendable, política e incluso moralmente ${ }^{46}$. Entender que las leyes abstractas o los planes políticos han de cumplirse a la letra, que toca al gobierno ocuparse de todos los problemas sociales y aun de los personales, favorece la intolerancia, aunque las gentes ordinarias, funcionarios, jueces y policías, no necesariamente sean personalmente intolerantes. Y al contrario: quizá

45 Escribe el radical y laico Piero IgNAzI: «Tiempo atrás, una aproximación de sabor católico de «comprensión y perdón» resolvió muchas situaciones críticas, [...] Ahora un egoísmo de banqueros ha prevalecido sobre la capacidad de mediación de los líderes políticos» (Piero IGNAzi, «Grecia: non poteva andare peggio», Eutopia, 2 de julio de 2015).

46 Es interesante que lo haya dicho precisamente un Papa, y en un momento difícil: PIO XII, alocución Ci Riesce a los juristas católicos italianos de 6 de diciembre de 1953, apartado V (accesible en internet): «Può Dio, (...) in alcuni casi scegliere il "non impedire » (...)? Può darsi che in determinate circostanze Egli non dia agli uomini nessun mandato, (...) non dia perfino nessun diritto d'impedire e di reprimere ciò che è erroneo e falso? (... L») ferrore e il peccato si trovano nel mondo in ampia misura. Iddio li riprova; eppure li lascia esistere. Quindi l'affermazione: Il traviamento religioso e morale deve essere sempre impedito, quando è possibile, perchè la sua tolleranza è in sè stessa immorale — non può valere nella sua incondizionata assolutezza. D'altra parte, Dio non ha dato nemmeno all'autorità umana un siffatto precetto assoluto e universale, nè nel campo della fede nè in quello della morale. Non conoscono un tale precetto nè la comune convinzione degli uomini, nè la coscienza cristiana, nè le fonti della rivelazione, nè la prassi della Chiesa. (...) Cristo (...) diede il seguente ammonimento: Lasciate che nel campo del mondo la zizzania cresca insieme al buon seme a causa del frumento (cfr. Matth. 13, 24-30). Il dovere di reprimere le deviazioni morali e religiose non può quindi essere una ultima norma di azione. Esso deve essere subordinato a più alte e più generali norme, le quali in alcune circostanze permettono, ed anzi fanno forse apparire come il partito migliore il non impedire l'errore, per promuovere un bene maggiore». 
los medievales, otomanos y otros que hemos puesto como ejemplo de más tolerancia que la que suele reconocérsele, no fueran personalmente muy tolerantes; habrá habido de todo, como siempre. Pero lo que es seguro es que carecían de las ideas de que el gobernante pueda ni deba regularlo todo, ni extirpar por completo el mal, de que todos los asuntos son competencia del poder público, de que no se puede admitir ningún error ni desviación al llevar a la práctica la ley abstracta, y así sucesivamente. Y no les cabía duda — como no le cabía a nadie hasta hace relativamente poco, tal vez hasta pensadores como Thomas Paine- de que no todo tiene arreglo, de que el mal, la enfermedad, el error y la imperfección forman parte de la condición humana.

Intentaremos, por tanto, identificar algunos de esos factores, primero los favorables y a continuación los desfavorables.

Es favorable a la tolerancia, en primer lugar, la visión personalista, ya que se tolera a las personas más que a las ideas, acciones o instituciones: uno nunca tolerará el canibalismo, pero quizá tenga que tolerar a un ex-caníbal. Ese personalismo tiene ramificaciones: asociado con él está la razonable confianza en la naturaleza humana, escasa en el posthumanismo actual que no sólo no confía en la naturaleza humana sino que, al contrario, pretende superarla; para no insistir en que el propio estado confía más en las máquinas que en sus funcionarios. En tercer lugar, en la misma línea personalista está el respeto a la dignidad del hombre, de todo hombre, pues incluso delincuentes y degenerados conservarán siempre un inamisible resto de dignidad, así como el respeto a la libertad personal, que lleva, en la convivencia interpersonal, aceptar a los otros como son, entendiendo la libertad y las libertades como «vive y deja vivir».

Como hemos repetido - cuarto argumento-, prepara el terreno a la tolerancia el aceptar una inevitable dosis de imperfección humana; si la tolerancia no está de moda, escribe Gray, es porque nuestra postcristiana época no acepta que seamos criaturas imperfectas ${ }^{47}$. Dentro de asumir la imperfección, hay que asumir, en particular, la imperfección e insuficiencia de la ley y de la jurisdicción, con razonable lugar para la casuística. Quinto, y en el terreno jurídico: favorece también la tolerancia entender el Derecho en sentido más bien negativo (probibir más que ordenar, y prohibir lo menos posible) y con notable papel de la jurisprudencia, la equidad y los principios. Por último, juzgar, tener convicciones: unas

47 Gray, p. 27. Aceptar la imperfección va contra la idea actual, de origen ilustrado, de que algún día desaparecerán la tragedia y la miseria (Gray, p. 28). Añadamos que hoy, el remedio de toda miseria o necesidad se encarga al estado. En CERvantes o SHAKESPEARE se asombra uno de ver cuán humanos eran, cómo en sus personajes coexiste lo mejor con lo peor, y cómo aceptaban que el error y el fallo, incluso moral, eran parte de la vida, como el bien y el altruismo. Ambos fueron nada perfectos en sus vidas personales, y ambos trabajaban sobre un trasfondo antropológico muy humano y católico. 
cosas estarán bien y otras mal, y unos juzgarán las acciones de otro y las encontrarán buenas, malas, erróneas o inadmisibles, y sin embargo se abstendrán de impedirlas, o al menos desviarán o suavizarán el castigo. La neutralidad total no es un ideal, y no beneficia a nadie salvo a quien la administra.

Los factores desfavorables resultan aproximadamente de volver los anteriores del revés como un guante. Así, es desfavorable el perfeccionismo, en primer lugar. Se reprochaba al perfeccionismo ser cosa de los aristotélico-escolásticos (la vida buena), pero ahora hay otro perfeccionismo tecnocrático y económico, tan perfeccionista como el otro ${ }^{48}$ pero sin su elevación moral; por ejemplo, el afán de eliminar todo fraude fiscal, toda economía sumergida, todo accidente de tráfico, toda discriminación. Nada de eso puede conseguirse a este lado de la eternidad, igual que nunca se eliminará toda la estupidez o todo el odio, e intentarlo seriamente nos pondría en camino al totalitarismo. El jurista realista sabe que hasta la mejor constitución tiene fallos y que la ley nunca se cumplirá al cien por cien (y a veces, afortunadamente).

Contribuye también, en segundo lugar, al caldo de cultivo para la intolerancia la mentalidad legalista en el Derecho que hoy nuestros estudiantes traen de casa; la frase «la ley es la ley, y es para cumplirla» se ha convertido en moneda corriente $^{49}$, con lo cual la gente ya no juzga las leyes por su finalidad; no se contenta con que quede satisfecho el espíritu de la ley, no analiza, sino que cumple o incumple, blanco o negro. En tercer lugar, mencionaremos las actuales nociones como que los delitos que nunca prescriben, que dificulta el perdón, el olvido y la reconciliación. Cuarto, no hay que olvidar algunas posiciones como la preferencia por la abstracción racional; los derechos de la personalidad, que, como ya dijimos, nos piden «confórmate a un modelo humano o ético» acordado (en teoría) por la mayoría; la corrección política ${ }^{50}$, en sus muy diversas manifestaciones: tabaco, impuestos, velocidad, tal vez mañana la obesidad o el azúcar...

48 «Lo notable es, entonces, que la libertad de opinión bien puede resultar ser no el climax de la libertad tras siglos de censura, sino sólo un hito en el camino hacia cierta idea de más amplias perfecciones. Y estas«más amplias perfecciones» [...] parecen incluir un represiva dimensión intolerante de la libre discusión» (MINOGue, Servile Mind, pág. 129).

49 El modelo legalista de los derechos vuelve innegociables los conflictos porque son «unconditional entitlements (titularidades de derechos incondicionadas) no susceptibles de moderación»; no permiten la negociación política, sino «sólo la victoria incondicional o la rendición» (GRAY, pág. 34). Con todo, no es así siempre; como decíamos, el derecho a no ser condenado sin juicio no tiene por qué producir intolerancia. Pero esto nos devuelve al problema, ya mencionado antes, de si los derechos son todos iguales.

50 «Como demanda de una semántica conformidad de actitudes, este intento de homogeneizar la opinión, requiere de nosotros una respuesta más servil que razonada» (MINOGUE, Servile Mind, pág. 127). 
También es desfavorable a la tolerancia la desconfianza en el hombre, tanto en calidad de hombre como de ciudadano; la cultura de la sospecha, que dificulta la amistad cívica y acaba con la presunción de inocencia; el miedo; el no aceptar que siempre habrá un mínimo de riesgo e inseguridad, sea en viajar, sea incluso en caminar por la calle; así como otros aspectos de la posmodernidad: las diversas maneras de condicionar nuestro comportamiento como nudging, choice architecture y similares. Es también muy intolerante la cada vez más extendida política de gobernar the hearts and minds de la gente, aunque sea para combatir el terrorismo. Y no es menos negativa la política de la identidad y el reconocimiento, no porque no tengamos identidad, sino porque esa política no se conforma con respetar o tolerar sino que nos pide asumir y celebrar todas las identidades como buenas.

Por último, y aunque pueda parecer paradójico, hay que tener en cuenta el relativismo inmoderado de nuestros días: es un hecho que hoy hay más relativismo que nunca, y sin embargo la intolerancia crece. La explicación es que sin una mínima base moral compartida se hace más difícil basar las decisiones en algo común, de modo que éstas se vuelven más artificiales, más «imposiciones» minoritarias $^{51}$. Es algo semejante a la paradoja tocquevilleana: la religión es más necesaria precisamente en las democracias ${ }^{52}$.

¿Por qué unos factores, mentalidades, concepciones jurídicas, sistemas institucionales o actitudes personales favorecen el florecimiento de la tolerancia mientras que otros lo dificultan? ¿Por qué pudo darse el caso de que pueblos atrasados y nada democráticos practicasen más la tolerancia que nosotros, modernos, ilustrados y demoliberales? La naturaleza humana no cambia y por tanto es arriesgado decir que, por ejemplo, los musulmanes y cristianos, que se toleraron bastante en la España medieval, eran más tolerantes que las ilustradas gentes de hoy, que vivimos en estados modernos y democráticos. Ahora bien, si la naturaleza humana no cambia, las actitudes profundas y la visión del mundo sí pueden cambiar. Para evaluar la tolerancia política (más que la personal) y las dificultades ante las que hoy se encuentra, hay que tener en cuenta que nuestros ancestros de la Edad Media — por seguir con ese ejemplo— no eran mejores que nosotros,

51 «La ausencia de claridad moral fomenta un clima anti-liberal de comportamiento intolerante. En un mundo en el que los moralistas encuentran difícil diferenciar claramente entre lo correcto y lo incorrecto, $[\ldots .$.$] sin una gramática moral, la guía ética a menudo tiene un carácter$ forzado y artificial» (FUREDI, 171). «El cinismo acerca de las pretensiones de verdad [...], y el pesimismo acerca del status del conocimiento han disminuido la capacidad y la inclinación a tolerar. Una de las mas perturbadoras expresiones de este desarrollo es la repugnancia a tratar de los asuntos prescriptivos en la vida pública» (FUREDI, 193).

52 Sobre las Religiones, págs. 27 s. 
y en muchos aspectos eran peores. Pero, para empezar, los reyes no buscaban la uniformidad que hoy se busca (si es que no se impone). La uniformidad que pudiera conseguir el rey Antíoco (que la buscó, a su manera, en s. II a. C.), e incluso, diecinueve siglos después, el Conde-Duque de Olivares, era muy escasa en comparación con la que hoy nos impone la corrección política y el gobierno de las vidas personales. Los reyes no buscaban regularlo todo; ni siquiera Luis XIV. Nadie tenía la meta de una población mentalmente homogénea como se tiene hoy; incluso la manera de vestir y de hablar cambiaban en pocos kilómetros. Hasta la época aproximada de la Revolución Francesa no se tenía la idea moderna de la ley, loi o Gesetz, y menos todavía de su perfección; por el contrario, se daba por supuesta la falibilidad e imperfección de la ley escrita, así como su incumplimiento por lo menos parcial. En vez de decir «la ley es la ley, y es para cumplirla», como ahora en España, se decía «se acata (la ley) pero no se cumple», y todos sabían que cumplir la ley podía implicar, a menudo, interpretarla. El hombre, hoy, no puede ni educar a sus hijos como quiere, mientras que antes eso y muchas otras cosas quedaban al leal saber y entender de la gente, para bien o para mal. El mundo imperfecto era su vida real; ellos sabían que muchos objetivos no se conseguirían, y convivían con ello. No se podían imaginar que por dictar una ley, producir un programa político, o fabricar una ideología o una explicación del mundo, fuese éste a quedar configurado enteramente según ella. De nuevo, «el pasado es un país extraño», como hemos visto que decía Minogue, y, de nuevo, tanto para mal como para bien.

Han aparecido aquí varias veces diversos imperios y diversos estados. ¿Acaso tiene algo que ver la forma política y la «forma de estado» con la tolerancia y la intolerancia? En principio, y descontando los totalitarismos, parecería que no, pero acercando la lupa la realidad sugiere que los imperios romano, alemán, otomano y británico han dado más lugar a la tolerancia que los estados-naciones surgidos en Europa en los siglos XV-XVII, por las razones que ya han ido saliendo aquí (acomodación contra uniformidad, y demás que no procede repetir ahora).

\section{REFERENCIAS BIBLIOGRÁFICAS}

Hannah ARendT: «Estado Nacional y Democracia», Arbor CLXXXVI 742 (marzoabril 2010), págs. 191-194. (Original: 1963)

Aristóteles, Ética a Nicómaco, ed. de Araújo y Marías, Madrid, 1959

Paulo F. DA Cunha, A Constituiçao do Crime, Coimbra, Coimbra Editora, 1998

- Political Ethics and European Constitution, Heidelberg, Springer, 2015.

Frank Furedi, On Tolerance. A Defence of Moral Independence, Londres y NY, Continuum, 2011. 
M. A. Glendon, Rights Talk. The Impoverishment of Political Discourse, N. Y., The Free Press, 1991.

John Gray, Enlightenment's Wake. Politics and Culture at the close of Modern Age, Abingdon, Routledge, 2007.

James KALB, The Tyranny of Liberalism, Wilmington, 2008

- Against Inclusiveness, Tacoma, 2013.

Kenneth Minogue, The Servile Mind, NY y Londres, 2010.

Dalmacio Negro, Historia de las Formas del Estado, Madrid, 2010.

Yossi Nehushtan, Intolerant Religion in a Tolerant-Liberal Democracy, Oxford, 2015.

Hans OBerdiek, Tolerance: Between Forbearance and Acceptance, Lanham (Maryland), 2001.

A. C. Pereira Menaut, Lecciones de Teoría Constitucional, Madrid, Colex, 2010

- «Elogio de la Tolerancia (y de la Imperfección)», Mercurio Peruano 525-526 (2012-2013), 213-221.

A. C. Pereira Menaut y F. Martínez Arribas, « ¿Malos Tiempos para la Tolerancia? La Intolerancia latente en los Rescates Financieros en la Unión Europea hoy», Derecho Público Iberoamericano 2 (2013), 207-236.

A.C. Pereira Menaut y C. Pereira Sáez, Teoría Política, Santiago de Compostela, Andavira, 2015 (publ. también, con otros títulos, en Colombia, México y Perú).

— «Ley, Derecho y Paz Social: el caso de la Tolerancia», Notandum 41, mayoagosto 2016, 79-89.

María José Roca, La tolerancia en el Derecho, Madrid, Fundación Registral, 2009.

Richard STITH, «The Priority of Respect: How Our Common Humanity Can Ground Our Individual Dignity», 44 Int'l Phil. Q. 165 (2004)

Manfred Svensson, «A Defensible Conception of Tolerance in Aquinas?», The Thomist 75 (2011), págs. 291-308

Alexis De Tocqueville, Sobre las Religiones. Cristianismo, Hinduismo e Islam, ed. de J.-L. Benoît; trad. de F. Caro; Madrid, 2013

Title:

Simple Tolerance.

\section{Summary:}

BY WAY OF AN INTRODUCTION. A REMINDER. SOME PROBLEMS CONCERNING TOLERANCE: Tolerance and the Law. Tolerance and Rights. The Paradox of Tolerance. Tolerance and 
Relativism. Tolerance and Religion. BY WAY OF A CONCLUSION: SOME FACTORS FAVOURING OR HINDERING TOLERANCE. REFERENCES.

\title{
Resumen:
}

A pesar de las apariencias y proclamaciones oficiales, la tolerancia no está hoy de moda. Por ello lo primero que procede es recordar en qué consiste realmente y mostrar cómo es: asistemática, pluriforme, no estrictamente racional, e imprescindible para la vida social. Estudiaremos después la relación que tiene con el Derecho y con los derechos (que no es unívoca), así como los factores ambientales favorables o desfavorables. En cuanto al método, evitamos el razonamiento abstracto y buscamos el histórico y basado en la realidad.

\begin{abstract}
:
In spite of appearances and declarations to the contrary, toleration is a not altogether fashionable notion these days. We must, therefore, start by recalling what it really is. Further to that we shall show how it is: unsystematic, taking multiple forms, not strictly rational -- yet utterly essential for the smooth running of social life. We shall consider its relationship with Law as well as with rights, themselves hardly univocal, and liberties. We shall look at elements in today's environment that are both favourable and unfavourable to it. Our methodology will eschew abstraction and look to historical and concrete approaches that stick close to reality.
\end{abstract}

Palabras clave:

Tolerancia, Derecho, derechos, política, ley.

\section{Keywords:}

Toleration, Law, Rights, Politics, written laws. 
